\title{
Clinical outcomes of endoscope-assisted vitrectomy for treatment of rhegmatogenous retinal detachment
}

This article was published in the following Dove Press journal:

Clinical Ophthalmology

14 November 2017

Number of times this article has been viewed

\author{
Sho Yokoyama' \\ Takashi Kojima ${ }^{2}$ \\ Toshio Mori ${ }^{3}$ \\ Taisuke Matsuda' \\ Hiroyuki Sato ${ }^{3}$ \\ Norihiko Yoshida ${ }^{4}$ \\ Tatsushi Kaga' \\ R Theodore Smith ${ }^{5}$ \\ Kazuo Ichikawa ${ }^{6}$ \\ 'Department of Ophthalmology, Japan \\ Community Healthcare Organization \\ Chukyo Hospital, Nagoya, Japan; \\ ${ }^{2}$ Department of Ophthalmology, Keio \\ University School of Medicine, Tokyo, \\ Japan; ${ }^{3}$ Department of Ophthalmology, \\ lida Municipal Hospital, lida, Japan; \\ ${ }^{4}$ Department of Ophthalmology, \\ Japanese Red Cross Gifu Hospital, \\ Gifu, Japan; ${ }^{5}$ Department of \\ Ophthalmology, New York University \\ School of Medicine, New York, NY, \\ USA; ${ }^{6}$ Chukyo Eye Clinic, Nagoya, \\ Japan
}

Summary: We evaluated the clinical outcomes for ophthalmic endoscope-assisted vitrectomy in consecutive patients with uncomplicated rhegmatogenous retinal detachment (RRD). The primary success rate was $98.4 \%$ (125/127) without performing a posterior drainage retinotomy or using perfluorocarbon liquids (PFCL) for subretinal fluid drainage.

Purpose: To investigate the clinical outcomes of endoscope-assisted vitrectomy in patients with uncomplicated RRD.

Methods: We examined 127 eyes from consecutive patients who underwent repair of RRD by 23- or 25-gauge endoscope-assisted vitrectomy, with a minimum follow-up of 3 months. Eyes with the following criteria were excluded: Giant retinal tears, grade C proliferative vitreoretinopathy, dense vitreous hemorrhage, retinal detachment secondary to other ocular diseases, and prior retinal or vitreous surgery. All cases underwent subretinal fluid drainage, endolaser photocoagulation and fundus inspection were performed under ophthalmic endoscopic observation. Success rate, visual acuity, surgery time and complications were evaluated.

Results: Primary and final success rate was $98.4 \%$ (125/127) and 100\% (127/127), respectively, Surgery time was $59.6 \pm 26.3$ minutes. The best-corrected visual acuity significantly improved from $20 / 100$ to $20 / 20(P<0.0001)$. There were 2 cases $(1.6 \%)$ of creation of a peripheral drainage retinotomy and 4 cases $(3.1 \%$ ) of using PFCL to suppress movement of the detached retina, but there were no cases of creation of a posterior drainage retinotomy or using PFCL for subretinal fluid drainage. There was 1 case of presumed endophthalmitis after surgery. There were 12 hypotonous cases at postoperative day 1 and one of them needed additional scleral sutures at postoperative day 4 for prolonged hypotony.

Conclusion: The present study demonstrated the efficacy of endoscope-assisted vitrectomy for patients with uncomplicated RRD. To perform endoscope-assisted vitrectomy safely, sufficient closure of sclerotomies is necessary at the end of surgery.

Keywords: endoscope-assisted vitrectomy, endoscopic vitrectomy, ophthalmic endoscope, retinal detachment, rhegmatogenous retinal detachment

\section{Introduction}

Rhegmatogenous retinal detachment (RRD) is a potentially blinding ocular disease that occurs in 6.3 to 17.9 per 100,000 , with the highest incidence found in patients between 60 and 69 years of age. ${ }^{1}$ Treatment of RRD has been performed mainly by scleral buckling surgery and pars plana vitrectomy (PPV) with or without scleral buckling. Owing to technological advances of new microsurgical instruments, intraocular observational systems, perfluorocarbon liquids (PFCL), directional endolasers and silicone oil, the repair rate by PPV has improved while complications have decreased. ${ }^{2,3}$ 
There also has been a trend away from traditional buckling surgery to PPV..$^{2-8}$

Among the intraocular observational systems, the wideangle viewing system has the advantages of a panoramic and high-resolution view, ${ }^{9-11}$ and it has become a popular and standard system with PPV for RRD. ${ }^{12-15}$ On the other hand, the ophthalmic endoscope has the advantage of observation throughout the fundus without being influenced by anterior segment conditions. Several references showed its usefulness in complicated cases in which intraocular observation was difficult due to ocular trauma, ${ }^{16-18}$ corneal opacities, ${ }^{18-20}$ small pupil $^{21}$ and endophthalmitis. ${ }^{20,22}$ However, there is a paucity of data regarding endoscope-assisted vitrectomy in uncomplicated RRD cases. Sonoda et al reported the usefulness of endoscope-assisted vitrectomy in uncomplicated RRD cases in a small number of cases. ${ }^{23}$

The aim of the present study is to investigate the clinical outcomes of endoscope-assisted vitrectomy, including the success rate and complications in $>100$ cases with uncomplicated RRD.

\section{Materials and methods}

\section{Patients}

We retrospectively reviewed 127 cases from 127 consecutive patients (44 women, 83 men) who underwent repair of RRD using either 23- or 25-gauge PPV with ophthalmic endoscope at the Japan Community Healthcare Organization Chukyo Hospital between January 2014 and May 2015, with a minimum follow-up of 3 months. Exclusion criteria were as follows: eyes with macular hole, giant retinal tears of $>90$ degrees, grade $C$ proliferative vitreoretinopathy (PVR), dense vitreous hemorrhage that precluded the assessment of retinal breaks and retinal detachment (RD) preoperatively, and RD secondary to diabetic retinopathy, familial exudative vitreoretinopathy, retinal vein occlusion, atopic dermatitis or uveitis, previous vitreoretinal surgery, or a history of previous RD surgery.

The protocol of this retrospective study was approved by the Institutional Review Board of Japan Community Healthcare Organization Chukyo Hospital and was conducted in accordance with ethical standards as stipulated in the 1989 Declaration of Helsinki guidelines. Written informed consent was obtained from all participants and all data were coded prior to statistical analysis.

\section{Surgical technique}

All surgeries were performed by 6 surgeons. All surgical procedures were performed with topical anesthetic eye drops, and sub-Tenon's anesthesia. First, standard phacoemulsification and aspiration with/without intraocular lens (IOL) implantation were performed if the patient's fundus visualization was poor due to cataract. All patients underwent standard 3-port 23- or 25-gauge PPV using a Constellation Vision System (Alcon, Fort Worth, TX, USA) with Resight ${ }^{\circledR}$ 700 fundus viewing system (Carl Zeiss Meditec AG, Jena, Germany). All eyes underwent a core vitrectomy and peripheral vitreous dissection. Then an ophthalmic endoscope (FiberTech, Tokyo, Japan) and a backflush needle with a silicone tip were inserted. An FT-203F or FC-304/FL-301 (FiberTech) was used as the imaging system (camera and light source) of an ophthalmic endoscope. Before performing subretinal fluid drainage, the patient's head position was turned to the place where the primary retinal breaks were placed at the lowest part of the eyeball. Subretinal fluid was drained through the primary retinal breaks during fluid-air exchange (Figure 1). After sufficient drainage of subretinal fluid, endolaser photocoagulation was performed at the edge of the retinal breaks (Figure $2 \mathrm{~A}$ and B). Prophylactic
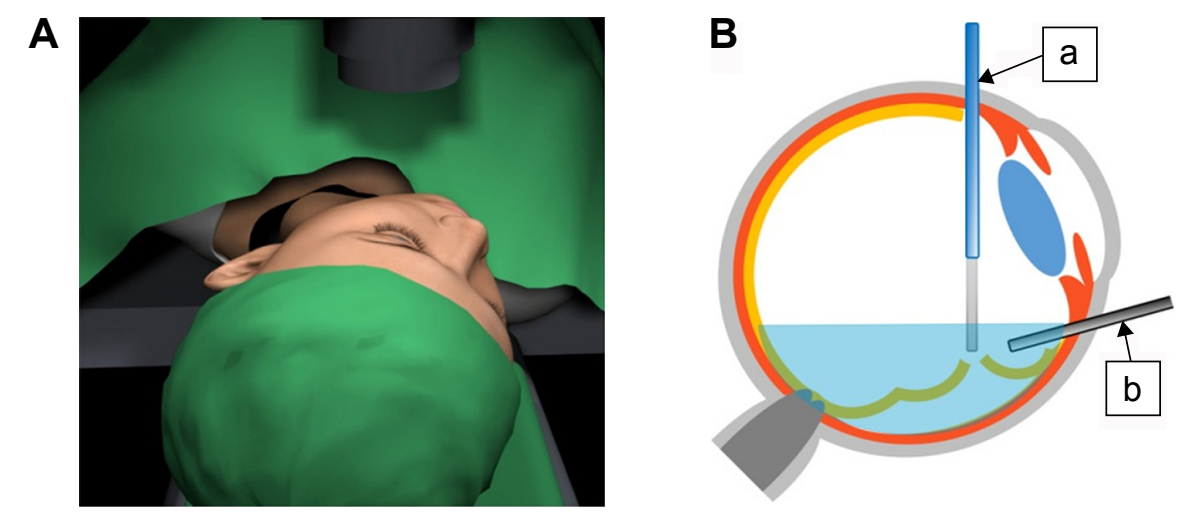

Figure I Procedure of ophthalmic endoscope-guided subretinal fluid drainage in pars plana vitrectomy for RRD.

Notes: (A) First, the patient's head is moved toward the position where the primary retinal break is located at the lowest level. In this position, subretinal fluid can easily come out from the retinal break into the vitreous space. (B) We mainly inserted the buckflash needle with a silicone tip (a) from the higher positioned port and the ophthalmic endoscopic probe (b) from the lower positioned port. But we used these instruments oppositely depending on the case or situation.

Abbreviation: RRD, rhegmatogenous retinal detachment. 

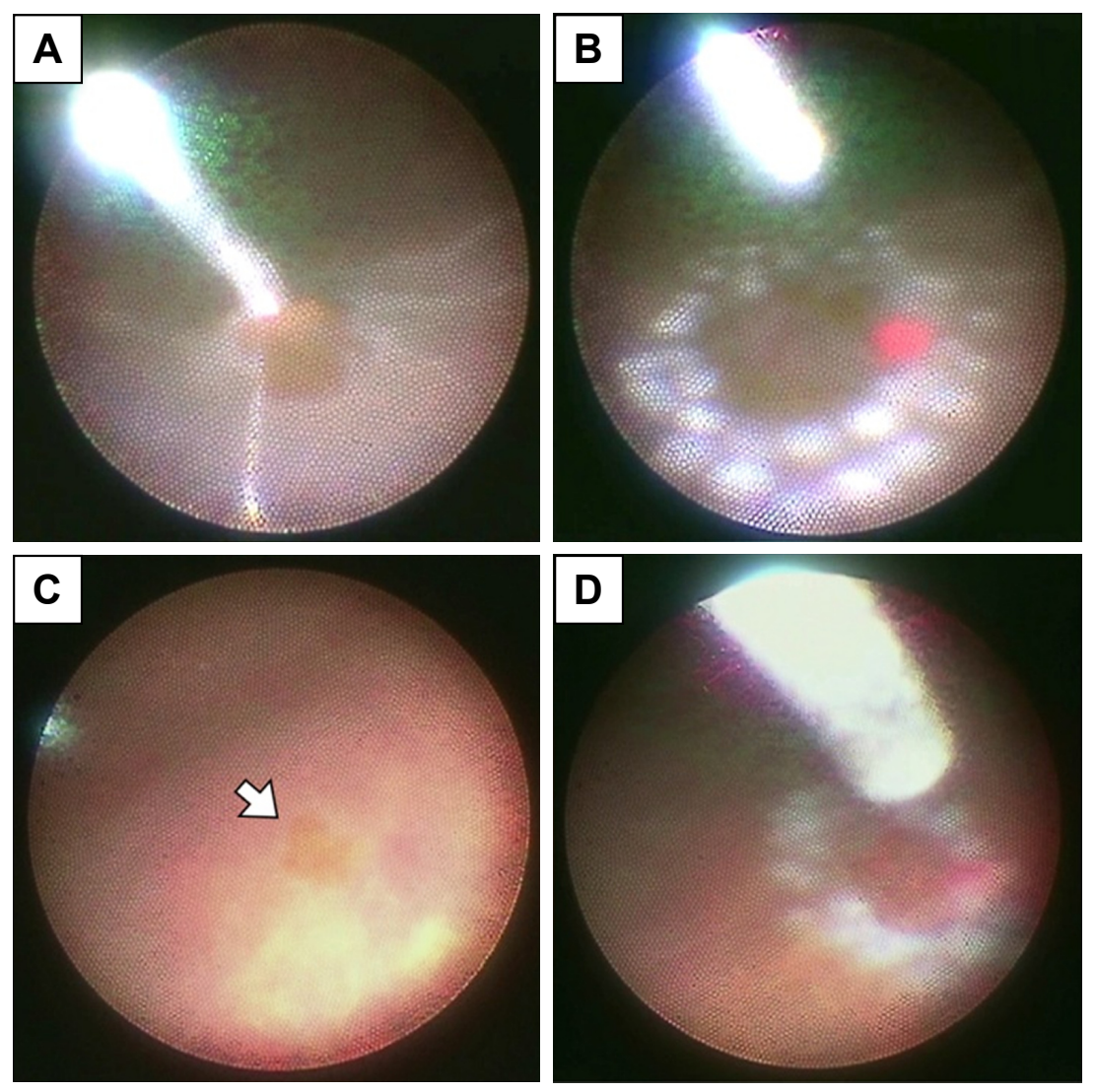

Figure 2 Representative images under the 25-gauge ophthalmic endoscope.

Notes: (A) Subretinal fluid drainage was performed through a primary retinal break during fluid-air exchange. (B) Endolaser photocoagulation was performed around the primary retinal break. (C) Small retinal tear was found at peripheral retina (arrow) during fundus inspection under the air condition. (D) Performing endolaser photocoagulation around the small retinal tear.

360-degree endolaser photocoagulation was not performed. Then the entire fundus was inspected under endoscopic guidance for any additional retinal tears, which were treated as needed with endolaser (Figure 2C and D). Subretinal fluid drainage, endolaser photocoagulation and fundus inspection were performed under ophthalmic endoscopic observation in all cases. Then the vitreous cavity was filled with either air, 20\% Sulfur Hexa-fluoride (SF6) gas or silicone oil (SILIKON ${ }^{\circledR} 1000$ Oil; Alcon). Silicone oil was mainly used for patients who could not reliably maintain prone positioning. At the end of surgery, the cannulas were removed, and the sclerotomies were closed with 8-0 polyglactin 910 (Vicryl $^{\circledR}$; Ethicon, Somerville, NJ, USA) sutures as needed. Patients were instructed to position either facedown or one side down for 3 to 7 days. In this study, there were no cases of cryopexy instead of endolaser photocoagulation or combined with scleral buckling.

\section{Patient outcomes}

Primary and final reattachment success rates were evaluated at 3 months after surgery. For eyes that were injected with silicone oil at the initial vitrectomy, reattachment was evaluated 3 months after silicone oil removal. Use of PFCL and creation of drainage retinotomy were also evaluated. Postoperative visual acuity was evaluated at the patient's final visit, surgical time and complications were recorded. In addition, we also compared the success rate, surgical time and complications between the 23 - and 25-gauge groups.

\section{Statistical analysis}

Statistical analysis was performed using GraphPad Prism (GraphPad Software, San Diego, CA, USA). Wilcoxon signed-rank test and Fisher's exact test were used for statistical analysis. A $P$-value of $<0.05(P<0.05)$ was considered statistically significant.

\section{Results}

Table 1 summarizes patient demographic information. The study included 127 eyes of 127 patients (83 men and 44 women), with a mean age of $57.8 \pm 11.0$ years (range 35-80 years). The lens status was phakic in 93 eyes and pseudophakic in 34 eyes. The macular status was macula on (75 eyes) and macula off (52 eyes). Quadrants of RD were 
Table I Characteristics of 127 eyes of 127 patients who underwent endoscope-assisted vitrectomy

\begin{tabular}{|c|c|}
\hline \multicolumn{2}{|l|}{ Age (years) } \\
\hline Mean \pm SD & $57.8 \pm 11.0$ \\
\hline Range & $35-80$ \\
\hline \multicolumn{2}{|l|}{ Gender, n (\%) } \\
\hline Male & $83(65.4)$ \\
\hline Female & $44(34.6)$ \\
\hline \multicolumn{2}{|l|}{ Lens status, n (\%) } \\
\hline Phakia & $93(73.2)$ \\
\hline IOL & $34(26.8)$ \\
\hline \multicolumn{2}{|l|}{ Macular status, n (\%) } \\
\hline On & $75(59.1)$ \\
\hline Off & $52(40.9)$ \\
\hline \multicolumn{2}{|c|}{ Quadrants of RD, n (\%) } \\
\hline I & I5 (II.8) \\
\hline 2 & $65(5 \mid .2)$ \\
\hline 3 & $39(30.7)$ \\
\hline 4 (including total RD) & $8(6.3)$ \\
\hline \multicolumn{2}{|c|}{ Scleral indentation, n (\%) } \\
\hline Yes & $50(39.4)$ \\
\hline No & $77(60.6)$ \\
\hline \multicolumn{2}{|c|}{ Perfluorocarbon, n (\%) } \\
\hline Yes & $4(3.1)$ \\
\hline No & $123(96.9)$ \\
\hline \multicolumn{2}{|c|}{ Creation of drainage retinotomy, n (\%) } \\
\hline Yes & $2(1.6)$ \\
\hline No & $125(98.4)$ \\
\hline \multicolumn{2}{|c|}{ Materials for tamponade, $\mathrm{n}(\%)$} \\
\hline Air & $53(4 \mid .7)$ \\
\hline SF6 & 71 (55.9) \\
\hline Silicone oil & $3(2.4)$ \\
\hline \multicolumn{2}{|l|}{ Scleral suture, n (\%) } \\
\hline Yes & $29(22.8)$ \\
\hline No & $98(77.2)$ \\
\hline \multicolumn{2}{|l|}{ Gauge, n (\%) } \\
\hline 23-gauge & $93(73.2)$ \\
\hline 25 -gauge & $34(26.8)$ \\
\hline
\end{tabular}

Abbreviations: IOL, intraocular lens; RD, retinal detachment; SF6, sulfur hexafluoride.

15 eyes with 1 quadrant, 65 eyes with 2 quadrants, 39 eyes with 3 quadrants and 8 eyes with 4 quadrants (including total RD). In this study, 50 of 127 eyes (39.4\%) underwent scleral indentation at the time of peripheral vitrectomy, and 77 of 127 eyes $(60.6 \%)$ had peripheral vitrectomy under ophthalmic endoscopic guidance without scleral indentation. The surgical method for cutting peripheral vitrectomy was decided by the surgeon in each case. 4 cases (3.1\%) required PFCL to suppress movement of the detached retina during vitrectomy. 2 cases $(1.6 \%)$ required a peripheral drainage retinotomy because the primary retinal breaks were too small for subretinal fluid drainage. As for tamponade, air was used in 53 eyes, SF6 gas in 71 eyes and silicone oil in 3 eyes of patients who could not keep head position after surgery because of old age or lumbago. Silicone oil was removed within 3 months. Twenty-nine eyes (22.8\%) needed scleral sutures at the end of surgery. Ninety-three eyes $(73.2 \%)$ and 34 eyes (26.8\%) underwent vitrectomy in the 23 - and 25-gauge group, respectively.

\section{Anatomical outcomes}

Primary success rate was 98.4\% (125/127) and final success rate was $100 \%(127 / 127)$. Two patients required reoperation after initial surgery. In 1 case, the retina was attached after the initial vitrectomy but redetachment occurred 1 month later. The reason for redetachment was suspected to be reopening of the primary retinal tear by residual vitreous traction. We thus performed a 23-gauge endoscopic re-vitrectomy, cut the remaining vitreous as much as possible, drained subretinal fluid, added photocoagulation, and filled the eye with SF6 gas, resulting in final repair of the RD. In the second case, a small amount of subretinal fluid remained soon after initial vitrectomy, although the primary original retinal tear was closed. However, subretinal fluid increased and the RD worsened, so we performed 23-gauge endoscopic re-vitrectomy at 3 weeks after initial vitrectomy. During surgery, we found a small retinal tear in the inferior peripheral retina. Then we drained the subretinal fluid completely through it, added photocoagulation, and filled with SF6 gas; after secondary surgery, RD was also repaired in this case. As shown in Table 2, these 2 cases were treated with 23-gauge vitrectomy, but there was no significant difference in primary success rate between 23- and 25-gauge groups $(P=1.0)$.

\section{Visual function}

The mean best-corrected visual acuity (BCVA) significantly improved after surgery; in the total group from $20 / 100$ to $20 / 20(P<0.0001)$, in the macular on group from $20 / 30$ to $20 / 20(P<0.0001)$ and in the macular off group from $20 / 310$ to $20 / 30(P<0.0001)$ (Table 3$)$.

Table 2 Overall and comparison of postoperative success rates between 23- and 25-gauge group

\begin{tabular}{|c|c|c|c|c|}
\hline & Total, n (\%) & 23-gauge, n (\%) & 25-gauge, n (\%) & P* \\
\hline Primary success rate & $125 / 127$ (98.4) & $91 / 93$ (97.8) & $34 / 34(100)$ & 1.0 \\
\hline Final success rate & $127 / 127(100)$ & $93 / 93(100)$ & $34 / 34(100)$ & - \\
\hline
\end{tabular}

Note: *Fisher's exact test. 
Table 3 Visual acuity outcomes

\begin{tabular}{llll}
\hline & $\begin{array}{l}\text { Preoperative } \\
\text { BCVA, (logMAR) }\end{array}$ & $\begin{array}{l}\text { Postoperative } \\
\text { BCVA, (logMAR) }\end{array}$ & \\
\hline Macular on & $20 / 30(0.16)$ & $20 / 20(-0.02)$ & $<0.0001$ \\
Macular off & $20 / 310(1.19)$ & $20 / 30(0.18)$ & $<0.0001$ \\
Total & $20 / 100(0.66)$ & $20 / 20(0.05)$ & $<0.0001$ \\
\hline
\end{tabular}

Notes: *Wilcoxon signed-rank test. Visual acuity values are shown as Snellen visual acuity.

Abbreviations: BCVA, best-corrected visual acuity; logMAR, logarithm of the minimum angle of resolution.

\section{Surgical time}

Mean surgical time was $59.6 \pm 26.3$ minutes for all cases. $60.5 \pm 25.6$ minutes and $57.1 \pm 28.5$ minutes for the $23-$ and 25 -gauge group, respectively. There were no significant differences between the 2 groups $(P=0.40)$. In this study, 4 methods of surgery were performed: 1) vitrectomy with phacoemulsification and IOL implantation, 2) vitrectomy with phacoemulsification, 3) vitrectomy for IOL patients, and 4) lens sparing vitrectomy. For all 4 surgical methods, there were no significant differences in surgery times between 23 - and 25 -gauge groups $(P=0.77,0.53,0.73$ and 0.83$)$ (Table 4).

\section{Complications}

Table 5 shows a summary of intraoperative and postoperative complications. There were no cases showing severe intraoperative vitreous hemorrhage or choroidal detachment in this study. However, there was 1 case in which the crystalline lens developed a faint local opacity after surgery, probably due to instrument touch; in this case, cataract surgery was not performed because final BCVA was fairly good (20/25). There was 1 case of dense vitreous hemorrhage postoperatively, but it spontaneously cleared and disappeared completely at postoperative day 16 , and the final BCVA was 20/30. We observed 1 case of presumed endophthalmitis after surgery. In that case, vitrectomy with phacoemulsification and IOL implantation were performed as the initial surgical intervention. Slight inflammation in the anterior chamber was noted at postoperative day 1 , but the inflammation got worse with progressive fibrin formation in the anterior chamber up to day 5. As we suspected postoperative endophthalmitis, we performed 23-gauge endoscopic re-vitrectomy on that day. The IOL was removed and a silicone oil tamponade was performed, but RD was not found during surgery. Bacterial and fungal cultures of the IOL and vitreous were negative. The inflammation then gradually subsided, and we performed silicone oil removal and IOL implantation 2 months later. One year after initial surgery, the final BCVA was 20/20. There were 12 hypotonous cases (equal or $<5 \mathrm{mmHg}$ ) at postoperative day 1 in this study, 11 in the 23-gauge group and 1 in the 25 -gauge group. At postoperative day 3, there were 3 hypotonous cases, 2 in the 23-gauge group and 1 in the 25 -gauge group. One case in the 23 -gauge group showed sustained hypotony at day 4 due to leakage from the sclerotomy site for infusion port, which responded to suturing. Except for this case, all patients spontaneously returned to normal IOP, and no cases showed choroidal detachment. There were no significant differences in the incidence rates of hypotony at postoperative day 1 and 3 between the 23 - and 25 -gauge groups ( $P=0.18$ and 1.0, respectively).

\section{Discussion}

In the present study, we investigated the clinical outcomes of endoscope-assisted vitrectomy for patients with uncomplicated RRD. The primary success rate was $98.4 \%$ (125/127), consistent with other case studies of small-gauge vitrectomy. ${ }^{14,15,24,25}$ In these previous studies, a posterior drainage retinotomy was performed or PFCL was used for subretinal fluid drainage. The retinotomy could lead to intraoperative bleeding, secondary $\mathrm{PVR}^{26,27}$ and postoperative loss of visual field. ${ }^{26}$ PFCL may be toxic to the photoreceptors, the retinal pigment epithelium (RPE) and the cornea, ${ }^{28,29}$ and occasionally can be displaced subretinally. ${ }^{30}$ Moreover, subfoveal PFCL retention has been reported to be associated with poor visual outcome because of its potential toxicity. ${ }^{28,31}$

One of the advantages in endoscope-assisted vitrectomy is that it enables us to perform subretinal fluid drainage

Table 4 Comparison of surgical time between 23- and 25-gauge group in different surgical procedures

\begin{tabular}{lllll}
\hline Surgical methods & $\begin{array}{l}\text { Overall } \\
\text { min, mean } \pm \text { SD }(\mathbf{n})\end{array}$ & $\begin{array}{l}\text { 23-gauge } \\
\text { min, mean } \pm \text { SD }(\mathbf{n})\end{array}$ & $\begin{array}{l}\text { 25-gauge } \\
\text { min, mean } \pm \text { SD (n) }\end{array}$ \\
\hline $\mathrm{P}+\mathrm{I}+\mathrm{V}$ & $59.3 \pm 24.4(32)$ & $59.7 \pm 23.7(23)$ & $58.2 \pm 27.7(9)$ \\
$\mathrm{P}+\mathrm{V}$ & $67.5 \pm 26.9(30)$ & $67.0 \pm 27.3(27)$ & $72.3 \pm 26.7(3)$ \\
V (for IOL patients) & $61.2 \pm 27.5(34)$ & $62.7 \pm 26.2(25)$ & $57.1 \pm 32.4(9)$ & 0.77 \\
V (lens sparing) & $50.6 \pm 24.8(3 \mathrm{I})$ & $49.1 \pm 22.4(18)$ & $52.8 \pm 28.7(13)$ & 0.53 \\
Total & $59.6 \pm 26.3(127)$ & $60.5 \pm 25.6(93)$ & $57.1 \pm 28.5(34)$ & 0.73 \\
\hline
\end{tabular}

Note: *Wilcoxon signed-rank test.

Abbreviations: SD, standard deviation; P, phacoemulsification and aspiration; I, intraocular lens implantation; V, vitrectomy; IOL, intraocular lens. 
Table 5 Overall intraoperative and postoperative complication rates and comparison between 23 - and 25 -gauge group

\begin{tabular}{|c|c|c|c|c|}
\hline & $\begin{array}{l}\text { Overall } \\
\text { n (\%) }\end{array}$ & $\begin{array}{l}\text { 23-gauge } \\
\text { n (\%) }\end{array}$ & $\begin{array}{l}\text { 25-gauge } \\
\text { n (\%) }\end{array}$ & $P^{*}$ \\
\hline \multicolumn{5}{|c|}{ Intraoperative complication } \\
\hline Lens touch & $\mathrm{I}(0.8)$ & $\mathrm{I}(\mathrm{I} . \mathrm{I})$ & 0 & 1.0 \\
\hline \multicolumn{5}{|c|}{ Postoperative complication } \\
\hline Vitreous hemorrhage & $\mathrm{I}(0.8)$ & 0 & $\mathrm{I}(\mathrm{I} . \mathrm{I})$ & 1.0 \\
\hline Endophthalmitis & $\mathrm{I}(0.8)$ & $\mathrm{I}(\mathrm{I} . \mathrm{I})$ & 0 & 1.0 \\
\hline \multicolumn{5}{|l|}{$\operatorname{IOP}(<5 \mathrm{mmHg})$} \\
\hline POD I & $12(9.4)$ & II (II.8) & I (2.9) & 0.18 \\
\hline POD 3 & $3(2.4)$ & $2(2.2)$ & I (2.9) & 1.0 \\
\hline
\end{tabular}

Note: *Fisher's exact test.

Abbreviations: IOP, intraocular pressure; POD, postoperative day.

through the primary retinal breaks by tilting the patient's head position, without creating a posterior drainage retinotomy or using PFCL. In our study, there were only 2 cases in which we created a drainage retinotomy because the primary retinal tears were too small for subretinal fluid drainage, and even in such cases we could not need to create it at posterior retina but peripheral retina, so that these 2 patients did not have any complications, including visual field defects. There were a few patients (4 out of 127 eyes) for whom PFCL was used during surgery; in all these cases, we used PFCL only to suppress movement of the detached retina during vitrectomy not to drain subretinal fluid, and there was no PFCL retention afterward. In a few cases, the viscous subretinal fluid could not be drained completely due to old RRD, we realized that use of ophthalmic endoscope contributed to complete drainage of the subretinal fluid by changing the position of the patient's head without performing a posterior drainage retinotomy or using PFCL. There are several reports that incomplete drainage of subretinal fluid does not influence the anatomical success rate. ${ }^{32-34}$ On the other hand, there are other reports that subretinal fluid could cause an inflammatory reaction and cause proliferation of the retinal glial and RPE cells, ${ }^{35,36}$ which may lead to the onset of epiretinal membrane and PVR, and persistent metamorphopsia after surgery. ${ }^{37}$

Another advantage of endoscope-assisted vitrectomy is elimination of overlooked retinal breaks regardless of anterior segment conditions. Although corneal haziness and/or a droplet on the IOL may occur during surgery, the ophthalmic endoscope can still observe the fundus clearly. The resolution of ophthalmic endoscopic images is less than that of microscopic images, but is compensated by the magnification achieved by bringing the endoscopic probe close to the retina. In addition, the image quality is stable even under air. For these reasons, we believe that an ophthalmic endoscope enables the discovery of the small retinal tears or holes that can hardly be detected by microscopic observation after air/gas exchange. These advantages of endoscope-assisted vitrectomy may have contributed to the favorable success rates in the present study.

In this study, we also evaluated the outcome between 23 - and 25-gauge groups. Although the 25 -gauge system had less device rigidity and less image quality than the 23-gauge system, the 25 -gauge group achieved a success rate equal to or higher than that of the 23-gauge group. Surgery time in the 2 groups was not significantly different. Generally, vitrectomy with a smaller gauge takes a longer time to cut and aspirate the vitreous. We speculated that the scleral woundclosure time in the 23-gauge group might be longer than in the 25 -gauge group, thus equalizing total surgery time.

With respect to complications, there was 1 case in which the crystalline lens developed a faint local opacity after surgery, probably due to an instrument touch. However, we think the endoscopic vitrectomy can observe the lens and avoid its damage during the manipulation of anterior vitreous, so the endoscopic vitrectomy may be a good indication to cut anterior vitreous, especially when treated by lens-sparing fashion. We need to further evaluate the effects of endoscopic vitrectomy on lens-sparing surgery in the future.

There were 12 hypotonous eyes $(9.4 \%)$ at postoperative day 1 in this study; among them, 11 cases in the 23-gauge group and 1 case in the 25-gauge group. Although not reaching statistical significance between the 2 groups, 23 -gauge group tended to have postoperative hypotony more frequently. In contrast, previous reports about the hypotony rates after 23- or 25-gauge vitrectomy for RRD showed rates of $2-20 \%$ (including sutured or sutureless cases), ${ }^{38-41}$ which is similar to our study. In our study, we performed one or $>1$ scleral suture in 29 cases at the end of surgery, 23 cases in the 23-gauge group, and 6 cases in the 25-gauge group. Among these cases, 8 were sutured in the sclerotomy for infusion port, 16 in the right port and 21 in the left port. Thus, the sclerotomies for ports through which the instruments pass tended to need sutures. One possible reason could be the frequent need to tilt the instruments tangentially for endoscopic viewing of the periphery, causing deformation of the sclerotomies. Therefore, the hypotony may be associated with endoscopic surgery. At the end of endoscope-assisted vitrectomy, we need to confirm the complete closure of the sclerotomies. Further studies are needed to investigate the association between endoscope-assisted vitrectomy and postoperative hypotony. We also experienced a case with sustained hypotony due to leakage from 1 sclerotomy after surgery. The sclerotomy site was for an infusion port. Because 
of this, we think the hypotony, in this case, was not closely associated with the use of the ophthalmic endoscope.

We observed 1 case of presumed endophthalmitis after surgery. In this case, scleral sutures had been placed, and hypotony did not occur after surgery. However, the use of the ophthalmic endoscope increases the number of instrument passes through the sclerotomy sites during the surgery, which may result in deformation of the sclerotomy and increase the risk of endophthalmitis. For this reason, our single case of endophthalmitis could be associated with the endoscopic vitrectomy. Sufficient closure of the sclerotomies and infection precautions are clearly essential for a safe, endoscopeassisted vitrectomy. A large case-control study is needed to compare the complication rate between conventional vitrectomy and endoscopic vitrectomy in the future.

This study is limited by its retrospective nature, and the lack of a control group, that is, a comparison group undergoing vitrectomy for RRD without use of the ophthalmic endoscope. We need to perform a prospective, controlled study in the future. There were also no cases that underwent general anesthesia in this study. Under general anesthesia, there is a limitation of the head tilt for the drainage of subretinal fluid in the endoscopic vitrectomy. Therefore, we should evaluate cases under general anesthesia separately in a future study. In this study, we excluded complicated cases such as grade C PVR because the usefulness of the ophthalmic endoscope is established for such complicated cases. ${ }^{16-22,42}$ However, the literature includes only a small number of cases, so we need to evaluate clinical outcomes for large numbers of complicated cases in the future. In addition, there are several disadvantages to the ophthalmic endoscope itself. Because the endoscopic field of view is narrow and non-stereoscopic, there is a learning curve to its use. The differences in surgeons' experience may thus have affected the results in this study. Moreover, the resolution in ophthalmic endoscopic images are less than microscopic images. Although we stated that the ophthalmic endoscope could eliminate missed retinal breaks regardless of the anterior segment conditions, there is still the possibility that subtle changes, such as very small retinal holes, cannot be detected due to inadequate image resolution or the surgeon's lack of experience. Future advancement of the image quality of the endoscopic system may overcome this issue, further improving the clinical outcomes and shortening the learning curve. The cost of devices and marginal cost are additional burdens on the introduction of endoscopic vitrectomy to clinical practice. We need to study further the cost effectiveness of endoscope-assisted vitrectomy.
Recently, the heads-up 3-D vitrectomy system was developed, and will become available in the near future. ${ }^{43}$ There are common aspects of this system and the endoscopic vitrectomy system in that surgeons perform surgery while observing the monitor screen, but there are also unique advantages to both. Thus, if the heads-up 3-D vitrectomy system became common in the future, endoscopic images could be displayed together with the 3-D heads-up images on the same monitor screen, thus increasing the usefulness of both surgeries.

The present study also has several strengths: a large number of RRD cases were operated with nearly identical techniques, and any variation from the norm was noted precisely, with analysis of possible effects on the outcome. The advantages of the technique over conventional surgery were also well-defined and uniformly applied, namely, there were no posterior retinotomies or use of PFCL for subretinal fluid drainage.

\section{Conclusion}

The present study demonstrated a high success rate of endoscope-assisted vitrectomy, comparable with standard vitrectomy, for uncomplicated RRD. The manipulation of the scleral incisions with this technique appeared to cause occasional hypotony as a complication, which can be obviated by sufficient closure of the sclerotomies. The avoidance of performing a posterior retinotomy and using PFCL with this technique may, however, decrease the complications of visual field defect, PVR, or PFCL retention. A larger prospective, controlled study is indicated.

\section{Disclosure}

The authors report no conflicts of interest in this work.

\section{References}

1. Mitry D, Charteris DG, Yorston D, et al; Scottish RD Study Group. The epidemiology and socioeconomic associations of retinal detachment in Scotland: a two-year prospective population-based study. Invest Ophthalmol Vis Sci. 2010;51(10):4963-4968.

2. Wong CW, Wong WL, Yeo IY, et al. Trends and factors related to outcomes for primary rhegmatogenous retinal detachment surgery in a large asian tertiary eye center. Retina. 2014;34(4):684-692.

3. Ho JD, Liou SW, Tsai CY, Tsai RJ, Lin HC. Trends and outcomes of treatment for primary rhegmatogenous retinal detachment: a 9-year nationwide population-based study. Eye (Lond). 2009;23(3):669-675.

4. Lv Z, Li Y, Wu Y, Qu Y. Surgical complications of primary rhegmatogenous retinal detachment: a meta-analysis. PLoS One. 2015;10(3): e0116493.

5. Jonas JB, Mangler B, Decker A, Schlichtenbrede FC. Ratio of primary episcleral buckling surgery versus primary vitrectomy for rhegmatogenous retinal detachment. Eye Sci. 2014;29(1):53-54.

6. Kobashi H, Takano M, Yanagita T, et al. Scleral buckling and pars plana vitrectomy for rhegmatogenous retinal detachment: an analysis of 542 eyes. Curr Eye Res. 2014;39(2):204-211. 
7. Soni C, Hainsworth DP, Almony A. Surgical management of rhegmatogenous retinal detachment: a meta-analysis of randomized controlled trials. Ophthalmology. 2013;120(7):1440-1447.

8. Sun Q, Sun T, Xu Y, et al. Primary vitrectomy versus scleral buckling for the treatment of rhegmatogenous retinal detachment: a meta-analysis of randomized controlled clinical trials. Curr Eye Res. 2012;37(6): 492-499.

9. Inoue M. Wide-angle viewing system. Dev Ophthalmol. 2014;54:87-91.

10. Sato T, Kishi S, Otani T, Hashimoto H, Watanabe G. Modified technique for inducing posterior vitreous detachment through the posterior precortical vitreous pocket during microincision vitreous surgery with a wide-angle viewing system. Ophthalmologica. 2013;230(2):76-80.

11. Nakata K, Ohji M, Ikuno Y, et al. Wide-angle viewing lens for vitrectomy. Am J Ophthalmol. 2004;137(4):760-762.

12. Mohamed YH, Ono K, Kinoshita H, et al. Success rates of vitrectomy in treatment of rhegmatogenous retinal detachment. J Ophthalmol. 2016; 2016:2193518.

13. Mura M, Tan SH, De Smet MD. Use of 25-gauge vitrectomy in the management of primary rhegmatogenous retinal detachment. Retina. 2009;29(9):1299-1304.

14. Lai MM, Ruby AJ, Sarrafizadeh R, et al. Repair of primary rhegmatogenous retinal detachment using 25 -gauge transconjunctival sutureless vitrectomy. Retina. 2008;28(5):729-734.

15. Miller DM, Riemann CD, Foster RE, Petersen MR. Primary repair of retinal detachment with 25-gauge pars plana vitrectomy. Retina. 2008;28(7):931-936.

16. Sabti KA, Raizada S. Endoscope-assisted pars plana vitrectomy in severe ocular trauma. Br J Ophthalmol. 2012;96(11):1399-1403.

17. Chun DW, Colyer MH, Wroblewski KJ. Visual and anatomic outcomes of vitrectomy with temporary keratoprosthesis or endoscopy in ocular trauma with opaque cornea. Ophthalmic Surg Lasers Imaging. 2012;43(4):302-310.

18. Morishita S, Kita M, Yoshitake S, Hirose M, Oh H. 23-gauge vitrectomy assisted by combined endoscopy and a wide-angle viewing system for retinal detachment with severe penetrating corneal injury: a case report. Clin Ophthalmol. 2011;5:1767-1770.

19. de Smet MD, Mura M. Minimally invasive surgery-endoscopic retinal detachment repair in patients with media opacities. Eye (Lond). 2008; 22(5):662-665.

20. Ren H, Jiang R, Xu G, et al. Endoscopy-assisted vitrectomy for treatment of severe endophthalmitis with retinal detachment. Graefes Arch Clin Exp Ophthalmol. 2013;251(7):1797-1800.

21. Yoshitake S, Oh H, Kita M. Endoscope-assisted vitrectomy for retinal detachment in an eye with microcornea. Jpn J Ophthalmol. 2012; 56(6):613-616.

22. De Smet MD, Carlborg EA. Managing severe endophthalmitis with the use of an endoscope. Retina. 2005;25(8):976-980.

23. Sonoda Y, Yamakiri K, Sonoda S, Uchino E, Doi N, Sakamoto T. Endoscopy-guided subretinal fluid drainage in vitrectomy for retinal detachment. Ophthalmologica. 2006;220(2):83-86.

24. Yanyali A, Celik G, Dincyildiz A, Horozoglu F, Nohutcu AF. Primary 23-gauge vitreoretinal surgery for rhegmatogenous retinal detachment. Int J Ophthalmol. 2012;5(2):226-230.

25. Romano MR, Das R, Groenwald C, et al. Primary 23-gauge sutureless vitrectomy for rhegmatogenous retinal detachment. Indian $J$ Ophthalmol. 2012;60(1):29-33.

Clinical Ophthalmology

\section{Publish your work in this journal}

Clinical Ophthalmology is an international, peer-reviewed journal covering all subspecialties within ophthalmology. Key topics include: Optometry; Visual science; Pharmacology and drug therapy in eye diseases; Basic Sciences; Primary and Secondary eye care; Patient Safety and Quality of Care Improvements. This journal is indexed on Submit your manuscript here: http://www.dovepress.com/clinical-ophthalmology-journal
26. McDonald HR, Lewis H, Aaberg TM, Abrams GW. Complications of endodrainage retinotomies created during vitreous surgery for complicated retinal detachment. Ophthalmology. 1989;96(3):358-363.

27. Okada K, Sakata H, Mizote H, Minamoto A, Narai A, Choshi K. Postoperative posterior retinal holes after pars plana vitrectomy for primary retinal detachment. Retina. 1997;17(2):99-104.

28. Berglin L, Ren J, Algvere PV. Retinal detachment and degeneration in response to subretinal perfluorodecalin in rabbit eyes. Graefes Arch Clin Exp Ophthalmol. 1993;231(4):233-237.

29. Cauchi P, Azuara-Blanco A, McKenzie J. Corneal toxicity and inflammation secondary to retained perfluorodecalin. Am J Ophthalmol. 2005;140(2):322-323.

30. Garcia-Valenzuela E, Ito Y, Abrams GW. Risk factors for retention of subretinal perfluorocarbon liquid in vitreoretinal surgery. Retina. 2004; 24(5):746-752.

31. Lee GA, Finnegan SJ, Bourke RD. Subretinal perfluorodecalin toxicity. Aust N Z J Ophthalmol. 1998;26(1):57-60.

32. Chen X, Zhang Y, Yan Y, et al. Complete subretinal fluid drainage is not necessary during vitrectomy surgery for macula-off rhegmatogenous retinal detachment with peripheral breaks: a Prospective, Nonrandomized Comparative Interventional Study. Retina. 2017;37(3):487-493.

33. Gotzaridis S, Liazos E, Petrou P, Georgalas I. 25-Gauge vitrectomy and incomplete drainage of subretinal fluid for the treatment of primary rhegmatogenous retinal detachment. Ophthalmic Surg Lasers Imaging Retina. 2016;47(4):333-335.

34. Yamaguchi M, Ataka S, Shiraki K. Subretinal fluid drainage via original retinal breaks for rhegmatogenous retinal detachment. Can $J$ Ophthalmol. 2014;49(3):256-260.

35. Quintyn JC, Brasseur G. Subretinal fluid in primary rhegmatogenous retinal detachment: physiopathology and composition. Surv Ophthalmol. 2004;49(1):96-108.

36. Hirase K, Sugiyama T, Ikeda T, et al. Transforming growth factor beta(2) increases in subretinal fluid in rhegmatogenous retinal detachment with subretinal strands. Ophthalmologica. 2005;219(4):222-225.

37. Zhou C, Lin Q, Chen F. Prevalence and predictors of metamorphopsia after successful rhegmatogenous retinal detachment surgery: a crosssectional, comparative study. Br J Ophthalmol. 2017;101(6):725-729.

38. Susskind D, Neuhann I, Hilgers RD, et al. Primary vitrectomy for rhegmatogenous retinal detachment in pseudophakic eyes: 20-gauge versus 25-gauge vitrectomy. Acta Ophthalmol. 2016;94(8):824-828.

39. Zafar S, Mal W, Shakir M, Kamil Z, Bokhari SA, Rizvi SF. 23-gauge sutureless vitreo-retinal surgery for superior rhegmatogenous retinal detachment. J Coll Physicians Surg Pak. 2014;24(5):327-330.

40. Kusuhara S, Ooto S, Kimura D, et al. Intraocular gas dynamics after 20-gauge and 23-gauge vitrectomy with sulfur hexafluoride gas tamponade. Retina. 2011;31(2):250-256.

41. Colyer MH, Barazi MK, von Fricken MA. Retrospective comparison of 25-gauge transconjunctival sutureless vitrectomy to 20-gauge vitrectomy for the repair of pseudophakic primary inferior rhegmatogenous retinal detachment. Retina. 2010;30(10):1678-1684.

42. Kita M, Yoshimura N. Endoscope-assisted vitrectomy in the management of pseudophakic and aphakic retinal detachments with undetected retinal breaks. Retina. 2011;31(7):1347-1351.

43. Eckardt C, Paulo EB. Heads-up surgery for vitreoretinal procedures: an Experimental and Clinical Study. Retina. 2016;36(1):137-147.

PubMed Central and CAS, and is the official journal of The Society of Clinical Ophthalmology (SCO). The manuscript management system is completely online and includes a very quick and fair peer-review system, which is all easy to use. Visit http://www.dovepress.com/ testimonials.php to read real quotes from published authors. 